\title{
Chemistry and Art
}

\author{
Juraj Lipscher*
}

\begin{abstract}
This review summarizes possibilities of including scientific methods for investigation of art objects into the secondary school chemistry curriculum. We discuss methods such as X-ray radiography, infrared reflectography, neutron activation autoradiography, X-ray fluorescence, and Raman spectroscopy and provide recent examples of their use. The results obtained, especially when combined with modern digital image processing algorithms, are indeed impressive. The second part of the paper is devoted to suggestions for actual use in teaching. The activities in the classroom can be centered around scientific investigation of a single painting, properties and use of a single pigment, or utilizing parallels in the history of Chemistry and history of Art. Finally, scientific methods for detecting art fraud including actual historical examples are especially motivating for the students and various teaching activities can be designed around this aspect.
\end{abstract}

Keywords: Art fakes · Chemistry and art · Investigation of paintings · Science and art · Teaching chemistry

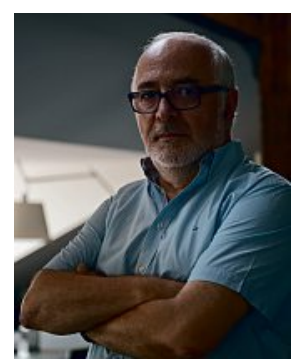

Juraj Lipscher was born in 1948 in Prague, former Czechoslovakia. He studied chemistry at the Slovak Technical University in Bratislava before emigrating to Switzerland in 1968. He continued his studies in chemistry at the University of Zurich, graduating with a $\mathrm{PhD}$ in 1982 under the supervision of Prof Dr. H. Fischer. After receiving the Diploma for Teaching at higher secondary schools (Höheres Lehramt) from the University of Zurich, he taught chemistry at the Kantonschule Baden from 1982 to 2014. During his professional career as a chemistry teacher, he was responsible for the exams in chemistry at the Swiss Federal Secondary School Exams (Schweizerische

\footnotetext{
*Correspondence: Dr. J. Lipscher

Kantonsschule Baden, Seminarstrasse 3, CH-5400 Baden (retired)

MINT-Lernzentrum der ETH Zürich, Clausiusstrasse 59, $\mathrm{CH}-8092$ Zürich (retired)

Current Address: Aarestrasse 29 A, 5102 Rupperswil

E-mail: juraj@lipscher.ch
}

Maturaprüfungen) (1993-today), a member of the Swiss Chemistry Commission (Deutschschweizerische Chemiekommission) (1997-2014), and participated in the education of future teachers at the ETH Zurich (Praktikumslehrer) (1999-2014). In 2010 he was awarded the Balmer Prize of the Swiss Chemical Society for innovations in the teaching of chemistry. From 2013 till today he is a research fellow at the MINT Learning Center of the ETH Zurich (Institute of Cognitive Studies, Prof. Dr. Elsbeth Stern).

\section{Introduction}

This paper is intended as a plea for widening the scope of interdisciplinary teaching and exploring the possibilities of teaching activities across the boundary between Humanities and Science. We have successfully conducted courses on subjects such as 'Time in Physics and Literature', 'Light in Science and Art', 'Order versus Disorder', [1] 'Crime and Science', [2] and 'Chemistry and Art'. [3]

The subject of 'Chemistry and Art' is particularly suitable in this respect, representing an exceedingly fruitful cooperation of Science and Art. An additional advantage lies in the intrinsically motivating effect of the aesthetic dimension of paintings and other works of art. Learning about isotopes, neutrons, and radioactivity while solving a mystery surrounding a painting by Rembrandt or Vermeer, definitely has its advantages. [4]

The author's website ColourLex ${ }^{[5]}$ contains a large amount of information pertinent to scientific investigation of paintings, a database of pigments, pigment analyses of paintings, and presentations on individual paintings and pigments intended for direct use in teaching.

\section{Scientific Investigation of Paintings ${ }^{[6]}$}

Works of art can be viewed in their artistic, art historical and social contexts. However, a painting is also a composite and multilayered material object consisting in most cases of the canvass or wood support, the various paint layers, and a final layer of varnish. As such, it can be investigated by scientific methods. Information gathered in a scientific investigation of a painting can enhance our understanding of the artwork and give us new insights into artist's painting technique and the genesis of the painting.

Imaging methods ${ }^{[7]}$ allow us to peek beneath the surface of the painting and depict its inner layers by employing radiation from different regions of the electromagnetic spectrum.

Analytical methods, ${ }^{[8]}$ comprising chemical analytical methods and the various spectroscopies, make it possible to identify the materials used by the artist in creating the painting (e.g. medium and pigments). The very modern Computational methods ${ }^{[9]}$ utilize mathematical algorithms to analyze the formal structure of the painting and to characterize the working method of the artist and facilitate the authentication of a painting. It is obvious that all these methods can be (and very much are) instrumental in detecting art forgeries.

The following paragraphs describe a choice of investigation methods from each of the above categories.

\subsection{X-Ray Radiography (XRR)[10]}

This classical method can be used to penetrate the whole body of the artwork including its support. The depth of penetration depends on the atomic numbers of the atoms present in the different layers of 
the painting. One of the most frequently used pigments in all art periods up to the nineteenth century was lead white (basic lead carbonate $\left.2 \mathrm{PbCO}_{3} \cdot \mathrm{Pb}(\mathrm{OH})_{2}\right)$. It was mainly employed in mixtures with other pigments to lighten their color or to paint the highlights in the scene. Due to the high atomic number of lead, X-rays are strongly absorbed by lead white. Thus, the more lead white pigment contained in an area of the painting, the lighter it appears in an X-ray radiograph. Another material that is quite opaque in the X-ray region of the spectrum is the red pigment vermilion (cinnabar, mercury sulfide $\mathrm{HgS})$.

\section{Example of Use}

A close inspection of the Renaissance painting 'The Feast of the Gods' by Giovanni Bellini ${ }^{11]}$ (Fig 1a) revealed several secrets lurking beneath its surface, the most important being the discovery that the original trees in the background on the left side were overpainted by Titian after Bellini's death (A). Bellini himself made several changes to the original composition as well, one of them being the erotization of the female figures originally dressed in a less frivolous way (B). The X-ray image clearly shows both changes (Fig 1b).

\subsection{Infrared Reflectography (IRR) and Infrared Photography (IRP) ${ }^{[12]}$}

Both methods make use of the fact that infrared radiation can penetrate the paint layers and thus reach the underdrawing layer. In many cases, the underdrawing is executed in a carbon-containing pigment such as charcoal or bone black that strongly absorbs the infrared radiation. Thus, the underdrawing of a painting is made visible and allows insights into the painting technique of the artist.

Films sensitive in the near infrared region of the electromagnetic spectrum were the first to be employed in the investigation of paintings. Originally the sensitivity of films in the infrared region of the spectrum was limited and did not exceed $900 \mathrm{~nm}$. The development of infrared sensitive cameras made it possible to extend the sensitivity range to up to $2000 \mathrm{~nm}$. Contemporary semiconductor-based infrared systems can utilize infrared radiation of a wavelength up to $3000 \mathrm{~nm}$. Contrary to the assumption that the longest wavelength brings the best images, the highest image quality can be obtained with the modern InGaAs sensors in the short-wave infrared (SWIR) region ranging from 900 to $1700 \mathrm{~nm}$. At longer wavelengths, the background noise of the omnipresent thermal radiation becomes too dominant.
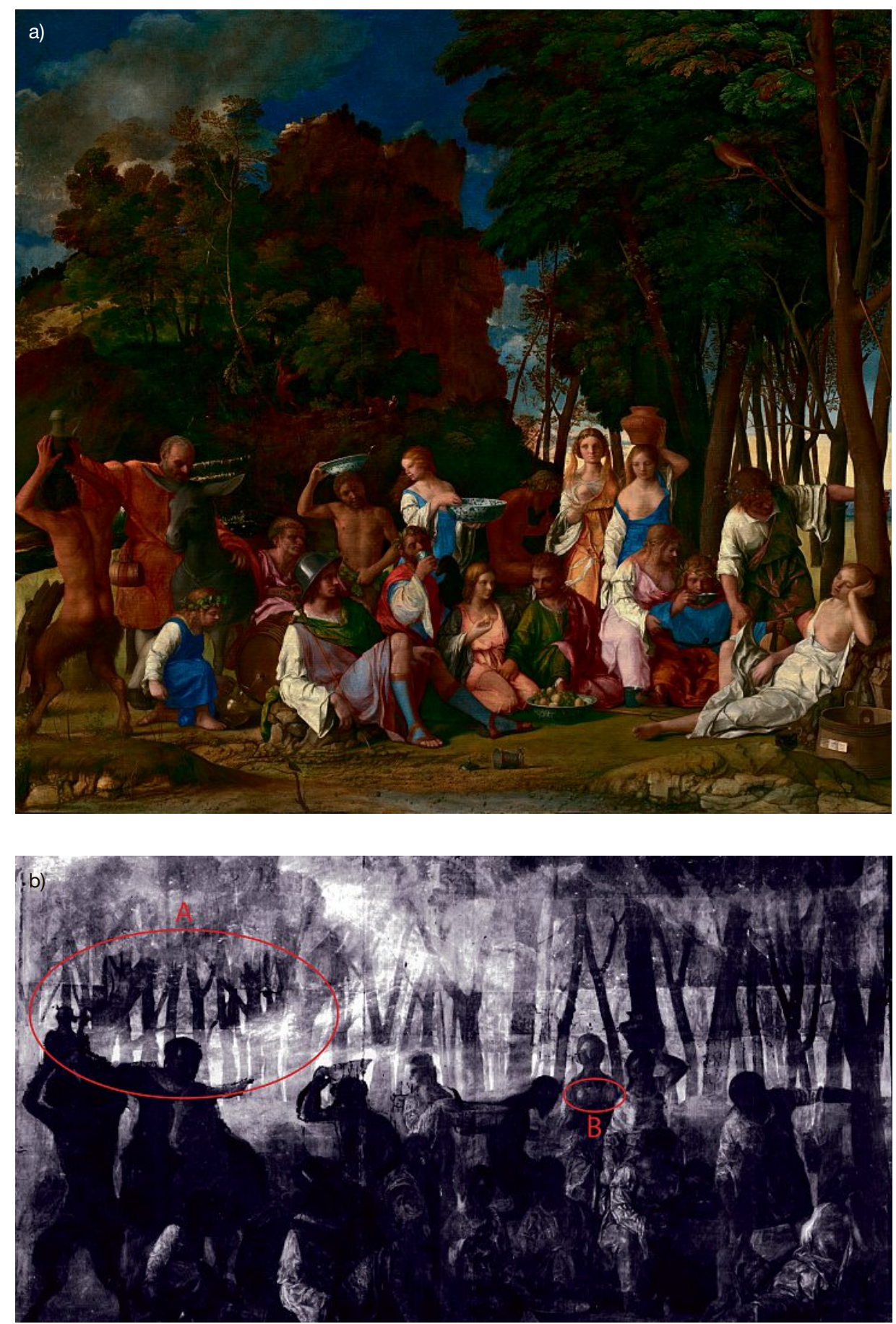

Fig 1. a) Giovanni Bellini and Titian, 'The Feast of the Gods', 1514-29. National Gallery of Art, Washington. Present state of the painting. (Image: Wikimedia Commons, public domain https:// commons.wikimedia.org/wiki/File:Feastofthegods.jpg). b) X-ray image of 'The Feast of the Gods'. Originally, Bellini's entire background consisted of single trees similar to those on the right side. Titian overpainted the left side after Bellini's death. The nymphs' dresses originally covered their breasts and were subsequently lowered by Bellini himself (B). (Image: Michael Douma, WebExhibits, used with the permission of the author)

\section{Example of Use}

One recent example of a fruitful and elegant use of SWIR is the investigation of Picasso's 'Blue Room' painted in 1901. Scientists at The Phillips Collection, National Gallery of Art, Cornell University, and Delaware's Winterthur Museum managed to obtain a high-quality IR image of a portrait of a well-dressed bearded man beneath the surface of the painting. ${ }^{[13]}$ This is a rather typical example of an artist reusing a canvass, mostly due to the lack of means for purchasing a new one. 


\subsection{Neutron Activation Autoradiography (NAAR) ${ }^{[14]}$}

The basic principle of this method can be summarized as follows: The painting is placed inside a special nuclear reactor where it is irradiated by slow neutrons. Neutrons are captured in the nuclei of the atoms constituting the pigments and make them weakly radioactive. After several hours, the painting is taken out of the reactor. Now the radioactive isotopes emanate radiation, which can be recorded on a film placed on the painting. The major advantage of neutron activation autoradiography is due to the different half-lives of the radioactive isotopes. Some isotopes such as ${ }^{66} \mathrm{Cu}$ decay very fast (minutes) and others such as the radioactive isotopes of mercury decay considerably slower (many days). Several films can be laid onto the painting consecutively, recording radiation of different isotopes and thus recording the distribution of the individual pigments in the painting.

\section{Example of Use}

The investigation of Johannes Vermeer's 'Woman with the Pearl Necklace', 1662-65 (Fig 2a) by NAAR ${ }^{[15]}$ has shown that Vermeer made significant changes to the painting during its creation. The film placed on the painting after 9 days and exposed for 42 days recorded the radiation of the isotope ${ }^{32} \mathrm{P}$ contained in the pigment bone black and the two isotopes of mercury ${ }^{197} \mathrm{Hg}$ and ${ }^{203} \mathrm{Hg}$ contained in the red pigment vermilion (Fig 2b). This film shows a map on the wall (A) and a lute on the chair (B), which are not visible in the painting in its present state.

\subsection{X-Ray Fluorescence (XRF) ${ }^{[16]}$}

When using this method, the sample is irradiated by an intense focused X-ray beam. The energy of the X-rays is sufficient to expel electrons from the inner shells. Electrons from outer shells subsequently fall into the empty orbitals left by the expelled electrons and emit X-rays in the process. As every atom has its own electronic structure, the energy of the emitted X-rays is characteristic for each element and can be used for its identification. The elements can then be tentatively assigned to the pigments most probably used in the painting, however, no unequivocal identification of pigments is possible.

XRF can be used for the identification of pigments in specific areas of a painting. It can also be employed to scan the whole painting at one wavelength characteristic for one specific element to obtain the distribution map for this element. This can be repeated for all elements contained in the usual pigments.

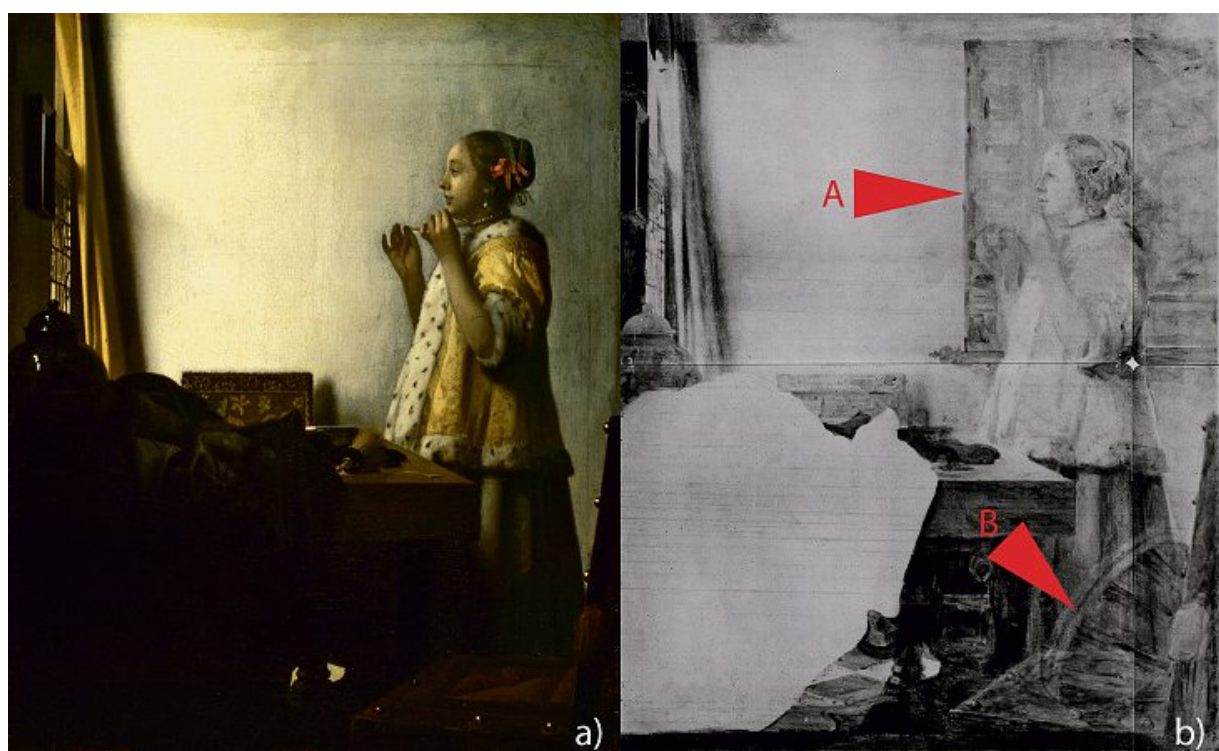

Fig 2. a) Johannes Vermeer, 'Woman with the Pearl Necklace', 1662-65, Gemäldegalerie Alte Meister Berlin. Present state of the painting. b) Neutron radiograph image showing the changes done by the painter in the course of his work. The map on the wall $(A)$ and the lute on the chair (B) were painted out by Vermeer. (Both images: Gemäldegalerie, Staatliche Museen Berlin and Helmholtz-Zentrum Berlin.)

\section{Example of Use}

The existence of the hidden painting beneath 'The Portrait of a Woman', 1876-80, by Edgar Degas[17] was suspected for a long time and confirmed by conventional X-ray radiography. The painting was then investigated by scanning XRF using a synchrotron as the source of high energy X-radiation. ${ }^{[18]}$ The elemental distribution maps for all relevant elements were then assigned to the most probable pigments. The information on the pigment distribution together with the known colors of the pigments were finally used for a digital reconstruction of the underlying painting. The quality of the obtained image is indeed stunning, especially in comparison with the classical X-ray image.

\subsection{Raman Spectroscopy (RS)[19]}

This classical method utilizes the inelastic scattering of laser light by molecules or ions. The wavelength of the scattered light differs from the wavelength of the incident light and this difference is dependent on the structure of the particle. Thus, the primary use of Raman spectroscopy is the identification of pigments and its great advantage is the availability of handheld instruments allowing flexibility in the recording of the spectra. It is also the method of choice for identification of organic pigments as the $\mathrm{X}$-ray fluorescence can only identify the different elements. This is useless with organic compounds which basically consist of the same elements.

In the recently developed Surface Enhanced Raman Spectroscopy (SERS), the sample is deposited on a nanostructured metallic surface leading to an increase of the sensitivity by a factor of $10^{4}$ up to $10^{8}$.

\section{Example of Use}

When Renoir's 'Portrait of Madame Léon Clapisson', 1883, was removed from its frame for conservation work at The Chicago Art Institute, traces of a red pigment were discovered in areas previously covered by the frame.[20] An investigation of this pigment by SERS revealed its identity: it was the unstable red pigment carmine. The researchers assumed that the carmine protected from light under the frame had remained unchanged but was destroyed elsewhere in the painting. Further investigation did indeed reveal decomposition products of carmine in the background areas of the painting. The information on the distribution of such decomposition products together with the known color of carmine was then employed to digitally reconstruct the painting. In the subsequent exhibition at the Art Institute, the painting was exhibited side by side with the digital print of the reconstruction so that the viewers could compare both versions and see how the painting might have looked at the time of its creation.

\section{Application in Teaching}

The following paragraphs provide an overview of possible applications of the discussed topics in teaching Chemistry and/or Art at secondary schools. 


\subsection{Focus on a Single Painting}

A single painting can be discussed in scientific, artistic, and art historic contexts. A good example could be George Seurat's 'A Sunday Afternoon on the Island of Grande Jatte', 1884-86 (Fig. 3).[21] It is a prime example of Pointillism, and as such interesting in the context of art history. Seurat almost solely used pigments of pure spectral colors and did not mix them on the palette as is usual in oil painting. Instead, he placed small dots of pure pigments close to each other so that the colors would be superimposed on the retina of the beholder. Another chemically interesting aspect is his use of the intensely yellow pigment zinc yellow (zinc potassium chromate $\mathrm{K}_{2} \mathrm{O} \cdot \mathrm{ZnCrO}_{4} \cdot 3 \mathrm{H}_{2} \mathrm{O}$ ) in some areas of the painting. The pigment started its discoloration shortly after the completion of the painting. There are two chemical reactions responsible for the discoloration. Acids can shift the chromate-dichromate equilibrium towards dichromate ions causing a color shift towards orange-brown.

$$
\begin{aligned}
& 2 \mathrm{CrO}_{4}^{2-}(\mathrm{aq})+2 \mathrm{H}^{+}(\mathrm{aq}) \leftrightarrows \mathrm{Cr}_{2} \mathrm{O}_{7}^{2-} \\
& (\mathrm{aq})+\mathrm{H}_{2} \mathrm{O}(\mathrm{l})
\end{aligned}
$$

Chromate ions can also be reduced to $\mathrm{Cr}^{3+}$ ions leading to a greenish-grey color. ${ }^{[22]}$

$$
\begin{aligned}
& \mathrm{CrO}_{4}^{2-} 4 \mathrm{H}_{2} \mathrm{O}+3 \mathrm{e}^{-} \rightarrow \mathrm{Cr}(\mathrm{OH})_{3} \\
& +5 \mathrm{OH}^{-}
\end{aligned}
$$

\subsection{Focus on a Single Pigment}

It should be stated here that most of the commonly used pigments in oil painting are out of bounds in school labs due to their toxicity. One of the few possible exceptions is Prussian blue. The pigment can easily be prepared and directly used for painting. Its structure is interesting in the context of complex ions, which also leads to the explanation of its intense blue color caused by the transfer of an electron within the crystal lattice (charge transfer). Examples of key paintings in which this pigment has been used can be discussed as well. The technique of cyanotype is a very interesting and aesthetically enticing aspect of Prussian blue. It can be practiced by students in the lab, the chemical reactions can be discussed, and it also can be used for entire art projects. ${ }^{[23]}$

\subsection{Focus on History}

The emergence of new art periods and movements can be perceived from a broader angle when juxtaposed with the history of science in general and chemistry in particular. Claude Monet painted his 'Impression, Rising Sun' in 1872 and this date can be viewed as the beginning of
Impressionism. ${ }^{[24]}$ The use of bright vivid colors was one of the hallmarks of the new movement. However, one could ask: Where did the vivid and colorful pigments come from? The answer can be found in the history of chemistry. The element cobalt was discovered in 1735 . Cobalt blue (cobalt(II) aluminate, $\mathrm{CoAl}_{2} \mathrm{O}_{4}$ ), a pigment used for depiction of water by most of the Impressionists, was first synthetized by Thénard in 1803. Cobalt violet (cobalt phosphate or cobalt arsenate) followed in 1859. The discovery of chromium in 1797 led to the beautiful green pigment viridian (hydrated chromium(III) oxide), chrome yellow (lead(II) chromate) and all other chromate pigments. Finally, cadmium yel- low has been in use since about 1840 after the discovery of the element in 1817.

\subsection{Forger's Workshop}

One group of students (the 'forgers') can prepare a fake painting employing a pigment not yet available during the given historic period. The other group (the 'scientists') analyzes the pigment and exposes the fraud. One possible example would be the use of Prussian blue for a painting from the Baroque period painted in the $17^{\text {th }}$ century (e.g. by Rembrandt, Vermeer, or Rubens). Prussian blue was not discovered until $1704^{[25]}$ and can easily be detected by the reaction with alkalis to form a brown precipitate of iron hydroxide.
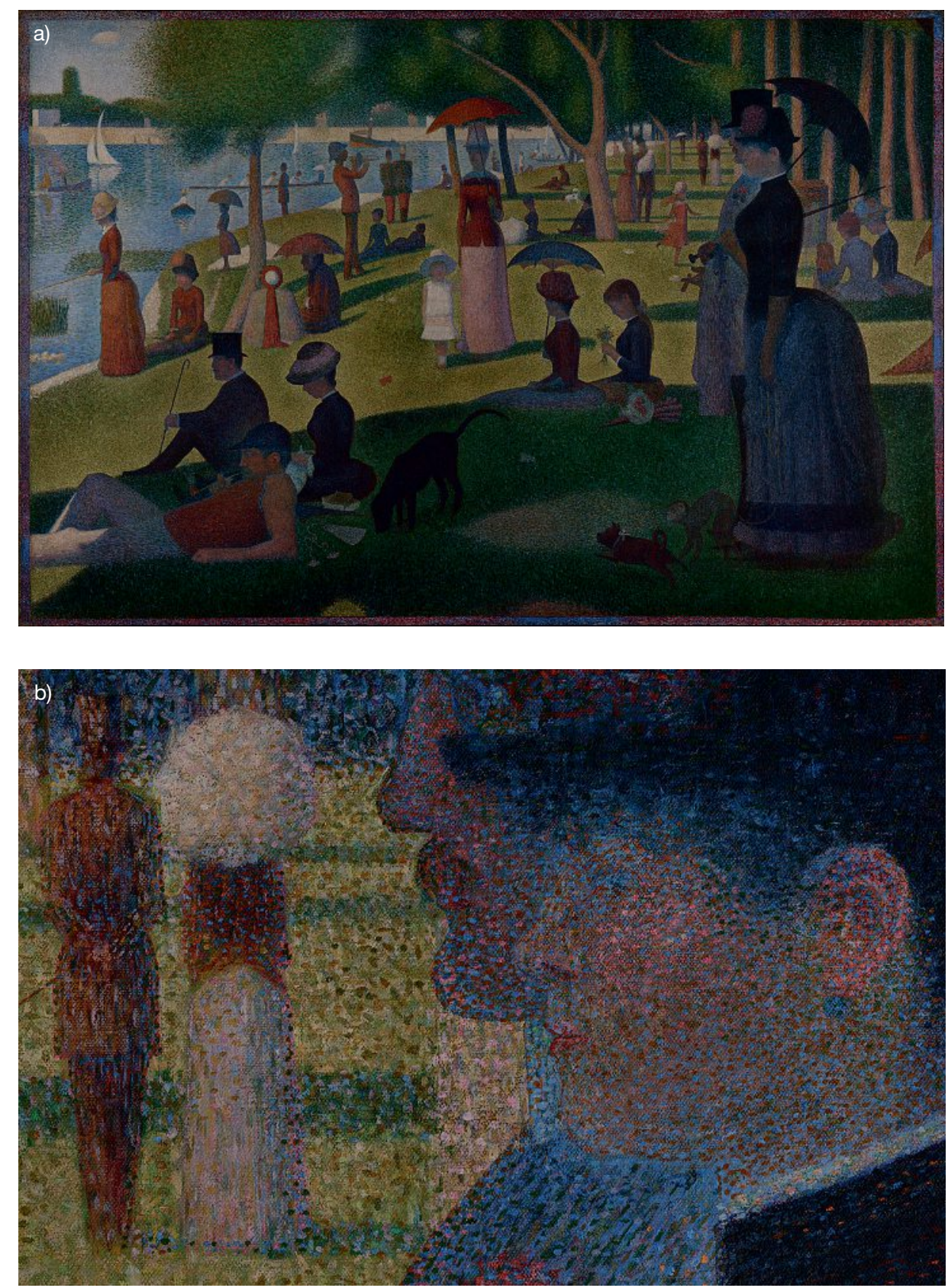

Fig 3 a). Georges Seurat, Sunday Afternoon on the Island of La Grande Jatte, 1884-86, Art Institute of Chicago. b) Detail of the painting showing the colored dots which superimpose on the retina of the viewer and form the desired color impression. (Both mages Wikimedia Commons, public domain https://commons.wikimedia.org/wiki/File:Georges_Seurat_-_A_Sunday_on_La_ Grande_Jatte_--_1884_-_Google_Art_Project.jpg 


\section{Conclusions}

Activities centered around the general area of Science and Art can be successfully employed when teaching Chemistry, Physics, and Arts in secondary schools. Advanced courses (Schwerpunktfach, Ergänzungsfach) and project-oriented teaching activities (Projektunterricht, Maturaarbeit) would best be suited to fully exploit the potential inherent in these areas.

The aesthetic dimension of a painting should not be underestimated in its influence on the motivation of our students. On the other hand, the teaching of complex scientific concepts can thus be embedded in a broader and relevant context. Additionally, the teaching activities described in this article widen the scope of interdisciplinary teaching and can help to bridge the schism between the Sciences and Humanities.

Finally, the impressive results of these contemporary scientific methods demonstrate the possibilities of modern Science and its indispensability in all human endeavors.

Received: September 24, 2017

[1] a) J. Lipscher, Chimia 1996, 50, 453; b) J. Lipscher, Praxis der Naturwissenschaften, Chemie in der Schule 2008, 57, 26.

[2] a) J. Lipscher, Praxis der Naturwissenschaften Chemie in der Schule 2004, 53, 2; b) J. Lipscher, D. Burger, A. Grunditz, P. Kaiser, S. Kamber, M. Nicca, A. Petrick, M. Spycher, Chem. unserer Zeit 1998, 32, 143.

[3] a) J. Lipscher, Praxis der Naturwissenschaften, Chemie in der Schule 2004, 53, 7; b) J. Lipscher, Praxis der Naturwissenschaften, Chemie in der Schule 2005, 54, 2.
[4] K. Trentelman, K. Janssens, G. van der Snickt, Y. Szafran, A. T. Woollett, J. Dik, Appl. Phys. A 2015, 121, 801.

[5] J. Lipscher, ColourLex, http://colourlex.com/, accessed 30.8.2017.

[6] National Academy of Sciences, Sackler NAS Colloquium, 'Scientific Examination of Art: Modern Techniques in Conservation and Analysis', 2005, Washington, DC: The National Academies Press. https://doi. org/10.17226/11413

[7] D. Gavrilov, R. G. Maev, D. P. Almond, Can. J. Phys. 2014, 92, 341.

[8] R. Mazzeo, 'Analytical Chemistry for Cultural Heritage', Springer International Publishing, 2017.

[9] D. Kim, S.-W. Son, H. Jeong, Sci. Rep. 2014, 4, 7370.

[10] M. Mantler, M. Schreiner, J. Radioanal. Nucl. Chem. 2001, 247, 635 .

[11] a) D. Bull, J. Plesters, J. C. Brown, L. Doumato, Studies in the History of Art $\mathbf{1 9 9 0 ,}$ 40,3 ; b) J. Lipscher, 'Giovanni Bellini and Titian, The Feast of the Gods', http:// colourlex.com/project/bellini-feast-of-thegods/, accessed 28.7.2017; c) M. Douma, 'Investigating Bellini's Feast of the Gods', http://www.webexhibits.org/feast/, accessed 10.8.2017.

[12] a) M. Faries, in 'Scientific Examination of Art: Modern Techniques in Conservation and Analysis', The National Academies Press, Washington, DC, 2005, p. 87; b) J. R. J. Van Asperen de Boer, J. Dijkstra, R. van Schoute, in 'Nederlands Kunsthistorisch Jaarboek', Vol. 41, 1990, p. 59, DOI: $10.1163 / 22145966-$ 90000173.

[13] P. A. Favero, J. Mass, J. K. Delaney, A. R. Woll, A. M. Hull, K. A. Dooley, A. C. Finnefrock, Heritage Sci. 2017, 5, 13 .

[14] a) A. Denker, C. Laurenze-Landsberg, K. Kleinert, B. Schröder-Smeibidl, in 'Neutron Methods for Archaeology and Cultural Heritage', Eds. N. Kardjilov, G. Festa, Springer International Publishing, Cham, 2017, p. 41, DOI: 10.1007/978-3-319-33163-8_3; b) E. V. Sayre, H. N. Lechtman, Stud. Conserv. 1968, $13,161$.
[15] C. Laurenze-Landsberg, in 'Inside the Camera Obscura - Optics and Art under the Spell of the Projected Image', Vol. 333, Ed. W. Lefèvre, Max Planck Institute for the History of Science, Berlin, 2007, p. 211.

[16] K. Janssens, M. Alfeld, G. V. d. Snickt, W. D. Nolf, F. Vanmeert, M. Radepont, L. Monico, J. Dik, M. Cotte, G. Falkenberg, C. Miliani, B. G. Brunetti, Annu. Rev. Anal. Chem. 2013, 6, 399.

[17] T. Gott, 'Edgar Degas's Portrait of a wom an', https://www.ngv.vic.gov.au/essay/edgar-degass-portrait-of-a-woman/, accessed 22.9.2017.

[18] D. Thurrowgood, D. Paterson, M. D. de Jonge, R. Kirkham, S. Thurrowgood, D. L. Howard, Sci. Rep. 2016, 6, 29594.

[19] a) H. Edwards, J. M. Chalmers, 'Raman spectroscopy in archaeology and art history', Royal Society of Chemistry, Great Britain, 2005; b) S. A. Centeno, J. Raman Spectrosc. 2016, 47 ,

[20] E. Stoye, 'Raman reveals Renoir's true colours', https://www.chemistryworld.com/research/ raman-reveals-renoirs-true-colours/7090.article, accessed 15.2.2014.

[21] a) R. L. Herbert, 'Seurat and the Making of La Grande Jatte', The Art Institute of Chicago in association with University of California Press, Berkeley, 2004; b) J. Lipscher, ColourLex, 'Georges Seurat, A Sunday Afternoon on the Island of La Grande Jatte', http://colourlex. com/project/seurat-la-grande-jatte/, accessed 10.8.2017

[22] F. Casadio, S. Xie, S. C. Rukes, B. Myers, K. A. Gray, R. Warta, I. Fiedler, Anal. Bioanal. Chem. 2011, 399, 2909

[23] a) A. Ludi, J. Chem. Educ. 1981, 58, 1013 b) J. Lipscher, ColourLex, 'Prussian Blue', http://colourlex.com/project/prussian-blue/, accessed 10.8.2017.

[24] J. Rewald, 'The History of Impressionism', Museum of Modern Art, New York, 1973

[25] A. Kraft, Bull. Hist. Chem. 2008, 33, 61. 